\title{
Factors Affecting the Academic Performance of Optometry Students in Mozambique.
}

James Loughman

Technological University Dublin, james.loughman@tudublin.ie

Kajal Shah

Technological University Dublin, kajshah@aol.com

Kovin Naidoo

Brien Holden Vision Institute, Durban, South Africa

See next page for additional authors

Follow this and additional works at: https://arrow.tudublin.ie/otpomart

Part of the Ophthalmology Commons

\section{Recommended Citation}

Loughman J. et al. (2015). Factors affecting the academic performance of optometry students in Mozambique. Optom Vis Sci. Jun;92(6):719-29. doi:10.1097/OPX.0000000000000606

This Article is brought to you for free and open access by ARROW@TU Dublin. It has been accepted for inclusion in Articles by an authorized administrator of ARROW@TU Dublin. For more information, please contact arrow.admin@tudublin.ie, aisling.coyne@tudublin.ie, gerard.connolly@tudublin.ie. 


\section{Authors}

James Loughman, Kajal Shah, Kovin Naidoo, and Luigi Bilotto

This article is available at ARROW@TU Dublin: https://arrow.tudublin.ie/otpomart/44 


\section{ARTICLE COVERSHEET \\ LWW_CONDENSED-FLA(8.125X10.875)}

\section{SERVER-BASED}

Template version : 7.5

Revised: 06/02/2014

Article : OPX14533

Typesetter : jesona

Date : Thursday April 16th 2015

Time : 02:12:29

Number of Pages (including this page) : 13 


\title{
Factors Affecting the Academic Performance of Optometry Students in Mozambique
}

\author{
Kajal Shah*, Kovin Naidoo $^{\dagger}$, Luigi Bilotto ${ }^{\ddagger}$, and James Loughman ${ }^{\S}$
}

\begin{abstract}
Purpose. The Mozambique Eyecare Project is a higher education partnership for the development, implementation, and evaluation of a model of optometry training at UniLúrio in Mozambique. There are many composite elements to the development of sustainable eye health structures, and appropriate education for eye health workers remains a key determinant of successful eye care development. However, from the first intake of 16 students, only 9 students graduated from the program, whereas only 6 graduated from the second intake of 24 students. This low graduation rate is attributable to a combination of substandard academic performance and student dropout. The aim of this article was to identify factors affecting the academic performance of optometry students in Mozambique.

Methods. Nine lecturers (the entire faculty) and 15 students ( 9 from the first intake and 6 from the second) were recruited to the study. Clinical competency assessments were carried out on the students, semistructured individual interviews were conducted with the course lecturers, and a course evaluation questionnaire was completed by students. The results were combined to understand the complexities surrounding the optometry student training and performance.

Results. One student out of nine from the first intake and three students out of six from the second were graded as competent in all the elements of the refraction clinical competency examination. Analysis of data from the interviews and questionnaire yielded four dominant themes that were viewed as important determinants of student refraction competencies: student learning context, teaching context, clinic conditions and assessment, and the existing operating health care context.

Conclusions. The evaluations have helped the university and course partners to better structure the teaching and adapt the learning environments by recommending a preparatory year and a review of the curriculum and clinic structure, implementing more transparent entry requirements, increasing awareness of the program, and improving Internet infrastructure.

(Optom Vis Sci 2015;92:00-00)
\end{abstract}

Key Words: optometry students, academic performance, Mozambique, teaching context, learning context, lecturer interviews, course evaluation questionnaire

n Africa up until the mid-1990s, only four countries conducted optometric training programs. ${ }^{1}$ Since 1997 , six more countries have established optometry courses. ${ }^{2}$ The Mozambique Eyecare Project is a higher education partnership for the development, implementation, and evaluation of a model of optometry training at UniLúrio in Mozambique. The 4-year course for the optometrists was based on a curriculum developed by the Brien Holden Vision Institute with competencies drawn from the optometry courses of the Dublin Institute of Technology (DIT) and the University of

*BSc(Hons), MCOptom

${ }^{\dagger} \mathrm{PhD}, \mathrm{OD}$

*OD

${ }^{\S} \mathrm{PhD}$

Dublin Institute of Technology, Dublin, Republic of Ireland (KS, JL); Brien Holden Vision Institute, Durban, South Africa (KN, LB); and African Vision Research Institute, University of KwaZulu-Natal, Durban, South Africa (KN, JL).
KwaZulu-Natal and the global competency-based framework of the World Council of Optometry. ${ }^{3}$

There are many composite elements to the development of sustainable eye health structures, and appropriate education for eye health workers remains a key determinant of successful eye care development. There are currently 95 students enrolled in the optometry degree program in UniLúrio, Nampula, in northern Mozambique. The first intake of 16 students, enrolled on this course, had to take a preparatory semester to remediate inadequacies in secondary school education that are manifest in some applicants to higher education. ${ }^{4}$ Legislative reform in Mozambique, implemented in 2009, has resulted in UniLúrio dropping the preparatory year for successive cohorts. However, from the first intake, only nine students graduated from the program, whereas only six graduated from the second intake of 24 students. This low graduation rate is attributable to a combination of substandard 
academic performance and student dropout. One student dropped out from the first intake and four from the second. Medical courses in Mozambique and science-based courses in other sub-Saharan African countries have reported similar graduation rates. ${ }^{5-7}$

There has been a considerable increase in the literature on factors that affect academic performance in recent years, ${ }^{8}$ but little that is specific to optometry undergraduates. ${ }^{9}$ Most of the published studies about teaching and learning in clinical courses have been conducted in North America and Europe, which are not directly applicable in developing countries because of the inevitable differences in curricula and education systems. Much of the recent research on student learning and performance in higher education has been summarized in terms of a 3P model of student learning: presage, process, and product. ${ }^{10-13}$ Presage defines the learning context including the learning environment (curriculum design, academic resources, and student-faculty interactions) and student characteristics (ability, motivation, and the quality of secondary education obtained). Process factors pertain to the students' approach to learning, whereas the product aspect is focused on the learning outcomes. It is also recognized that lecturers' conceptions of both teaching and learning also affect student learning outcomes. ${ }^{14}$

The implementation of the optometric training program in UniLúrio has required the partnership to face a number of key challenges. These include faculty recruitment (Portuguese or Spanish speaking); academic resource provision; the lack of awareness of, and student preparedness for, optometry education in a country with no prior experience or knowledge of optometry; and a challenging health care environment.

This article concentrates on the students' and lecturers' perceptions of the learning context, teaching context, and their impact on student performance within the fledgling optometry program in Mozambique. The student performance is contextualized by an evaluation of the refraction competencies of all 15 students in the final semester of their fourth year in UniLúrio, just before completion of the degree.

The aim of this article was to identify factors affecting the academic performance of optometry students in Mozambique. The use of semistructured interviews is useful for more in-depth lecturers' views on factors affecting student academic performance. ${ }^{7}$ The validity of student ratings is supported by the existence of a positive relation between student evaluation of the course and student achievement. ${ }^{15}$ This research will inform the course coordinators and partners on how to better structure the teaching and adapt the learning environments so that, in the future, student retention rates are higher and more students can graduate as optometrists that are competent in refraction, among other important skills.

\section{METHODS}

Nine lecturers and 15 students (nine from the first intake, cohort $\mathrm{A}$, and six from the second, cohort B) were recruited to the study comprising the entire faculty and all students who successfully graduated from the first 2 years of the program. The research was conducted according to the tenets of the Declaration of Helsinki. ${ }^{16}$ Clinical competency assessments were carried out on the students, semistructured individual interviews were conducted with the course lecturers, and a course evaluation questionnaire was completed by students. The results were combined to understand the complexities surrounding the optometry student training and performance.

\section{Competency Assessments}

Clinical evaluation consisted of direct observation of two clinic patients including one presbyope and one prepresbyope, assessed by two experienced graders. The time allowed was 50 minutes. The World Council of Optometry competency framework was used for these assessments. ${ }^{3}$ A checklist was used to grade the students. A pass-fail cutoff score of $75 \%$ for every skill was chosen based on literature. ${ }^{17}$ The skills were weighted according to their importance for safe and effective clinical practice. The weightings are reflected in Table 1 with $100 \%$ being the overall score. A variance of \pm 0.50 T1 diopters spherical equivalent was set as the limit of acceptability for retinoscopy and subjective refraction, according to accepted norms. ${ }^{18}$ The evaluations were administered 2 weeks before the final examinations, in the final year for each cohort.

\section{Semistructured Interviews with Course Lecturers}

All nine lecturers were interviewed face to face by the researcher and recorded. The interviews were conducted using a topic guide informed by teaching and learning literature. ${ }^{12,14}$ They began with a conversation about their educational background and their clinical and teaching experience. The concepts of teaching and learning were explored with questions on student capacity to learn (entry requirements, student feedback), course content (curriculum and any local circumstances that have to be considered for teaching this course and its contents), learning environment (resources available to support teaching and learning), and assessment. The aim was to obtain information relevant to student performance and the challenges that students face in the context of studying a new clinical course in a developing country.

\section{Course Evaluation Questionnaire for Students}

Existing questionnaires in use at the optometry faculties of the University of KwaZulu-Natal and DIT were used as the basis for the course evaluation questionnaire. It was reviewed for its relevance to Mozambique, by the researcher and the optometry course developers at the Brien Holden Vision Institute, and translated into Portuguese. It comprised 30 items and was designed based on the assumption that student performance (examination results and progression) is a function of ${ }^{15}$ :

a. Learning experience of the course module (four questions)

b. Lecturer teaching and support (eight questions)

c. Availability of learning resources (six questions)

d. Clarity of assessments and feedback (seven questions)

The questionnaire also required the student to grade the overall difficulty or ease of the optometry program and contained four open-ended questions that gave the students an opportunity to comment more openly.

The questionnaire used a five-point Likert scale, with response categories including the following: strongly disagree (1), disagree (2), 
TABLE 1.

Mean scores for clinical competency examination

\begin{tabular}{|c|c|c|c|c|}
\hline \multirow[b]{2}{*}{ Technique (weighting \%) } & \multicolumn{2}{|c|}{ Mean (SD) mark } & \multirow[b]{2}{*}{$\mathrm{p}^{*}$} & \multirow{2}{*}{$\begin{array}{l}\text { Students demonstrating } \\
\text { competency }(\mathrm{N}=15), \mathrm{n}(\%)\end{array}$} \\
\hline & Cohort A & Cohort B & & \\
\hline Communication (4\%) & $4(0)$ & $3.8(0.6)$ & 0.08 & $15(100)$ \\
\hline History and symptoms (10\%) & $8.2(1.9)$ & $7.5(2.6)$ & 0.49 & $14(93)$ \\
\hline Vision/visual acuity with old Rx (5\%) & $4.7(0.7)$ & $4.8(0.4)$ & 0.90 & $15(100)$ \\
\hline Pupillary distance $(2 \%)$ & $1.3(1)$ & $2(0)$ & 0.07 & $11(73)$ \\
\hline Pupil responses (2\%) & $1.8(0.5)$ & $1.8(0.6)$ & 0.84 & $13(87)$ \\
\hline Cover test $(2 \%)$ & $1.6(0.8)$ & $1.8(0.6)$ & 0.22 & $10(67)$ \\
\hline Ocular motility $(2 \%)$ & $1.8(0.5)$ & $2(0)$ & 0.24 & $14(93)$ \\
\hline Near point of convergence $(2 \%)$ & $1.2(1)$ & $1.7(0.8)$ & 0.14 & $9(60)$ \\
\hline External examination (5\%) & $4.2(0.9)$ & $3(2)$ & 0.19 & $10(67)$ \\
\hline Retinoscopy $(10 \%)$ & $6.8(3)$ & $5.5(3.6)$ & 0.30 & $9(60)$ \\
\hline Sphere $(10 \%)$ & $4.9(2.8)$ & $5.8(2.9)$ & 0.33 & $6(40)$ \\
\hline Cross-cylinder (10\%) & $2.6(2.4)$ & $3.9(2.8)$ & 0.17 & $4(27)$ \\
\hline Bin balance and near VA (4\%) & $1.2(0.9)$ & $2.3(1.3)$ & $0.02 *$ & $4(27)$ \\
\hline Final prescription and auxiliary tests (4\%) & $2.6(1.6)$ & $2.4(1.6)$ & 0.52 & $7(27)$ \\
\hline Advice to patient $(4 \%)$ & $2.4(1)$ & $2.1(1.6)$ & 0.88 & $5(33)$ \\
\hline Ophthalmoscopy (10\%) & $5.8(2)$ & $4.7(3.3)$ & 0.45 & $6(40)$ \\
\hline Recording (4\%) & $2.8(0.9)$ & $2.2(1.2)$ & 0.12 & $11(73)$ \\
\hline Management and time keeping (10\%) & $4.9(2.6)$ & $4.4(3)$ & 0.68 & $4(27)$ \\
\hline Total score $(100 \%)$ & $62.8(13.9)$ & $61.7(20.9)$ & & $4(27)$ \\
\hline
\end{tabular}

*Significant at $p<0.05$.

neutral (3), agree (4), and strongly agree (5). A mean score greater than 3 indicated agreement with the statement. ${ }^{15}$ It was piloted to 16 students from the first intake of optometry students and 24 students from the second intake of students from UniLúrio after completion of their first optometry module, vision and community, in the second semester of their first year. All participants were assured that their inclusion in the study was entirely voluntary and that they could withdraw their consent at any time.

AQ2 Minor amendments were made to the piloted questionnaire with the addition of certain items (evaluation of the students' clinical experience) with the final questionnaire having 48 items broken down into evaluation of five key categories: the lecturers (9 questions), the overall learning experience (14 questions), assessments (6 questions), learning resources and environment (8 questions), and the optometry program in general (3 questions). The questionnaire also asked the student to grade the course overall and contained seven open-ended questions, two on prior preparation for the program and five on general comments that gave the students an opportunity to comment more openly. The final questionnaire was administered to all the students a week before their final examinations in their final year.

\section{Data Analysis}

All data records were entered into a Microsoft Excel spreadsheet before being imported into SPSS version 21 for the quantitative statistical analysis. Descriptive statistics were computed for the clinical competency assessment, and the difference in performance between cohorts A and B was analyzed using a Wilcoxon signed rank test (significant at $\mathrm{p}<0.05$ ).

Reliability analyses were carried out using Cronbach $\alpha$ on the responses from the administered pilot and final questionnaire. ${ }^{19}$ Measures of central tendency and dispersion (mean and SD of scores), associated with each Likert scale statement in the questionnaire, were calculated. A Mann-Whitney $U$ test was conducted to compare the two cohorts to see if there was any difference in their responses $(p<0.05)$, which might account for any difference in student performance. For the qualitative questions on the student questionnaire, similar words and statements were highlighted while analyzing the response, themes were identified, and the frequency of each theme was counted.

For the lecturer interviews, the data extracts were transcribed verbatim, translated into English, read, coded, categorized, and analyzed thematically. The assigned themes were used for data presentation and representative quotes were selected. To improve the credibility of the data, member checking was used. ${ }^{20}$ This involved the data being presented to a focus group of lecturers to confirm the credibility of the themes and whether the overall account was realistic and accurate. Participants' comments were incorporated into the final narrative. The study was approved by the research ethics committee at DIT.

\section{RESULTS}

\section{Student Competency Examinations}

Table 1 summarizes the mean (SD) for both cohorts for every technique, the intercohort difference, and the total number of students passing every skill. One student (11\%) was graded as competent in all the elements of the refraction clinical competency examination from cohort A and three (50\%) from cohort B. Eight students from the first cohort and three from the second cohort failed to demonstrate competency in binocular balance, crosscylindrical refraction, and management and time keeping.

\section{Interviews with the Course Lecturers}

Four dominant themes emerged from the lecturer interview data that were viewed as important determinants of student 
performance from the lecturers' perspective: student learning context, teaching context, clinic conditions and assessment, and the existing operating health care context. The themes are presented

T2 with illustrative quotes from the nine lecturers (L1 to L9) in Table 2 and summarized below.

\section{Student Learning Context}

This theme highlighted the influence of the learning environment and student capacity to engage with learning.

\section{Learning Environment}

Some common themes were identified by the faculty to enhance the overall learning experience: the need for more lecturers, training on clinical skills for staff and students, and more teaching and learning resources.

\section{Student Capacity to Engage with Learning}

The factors affecting student performance included the student academic background and current entry requirements, lack of prior knowledge of the course and optometry practice, course workload and manageability, and student motivation. Inadequate student preparation and insufficient prerequisite knowledge of science and maths appeared to be the main reasons why the students had difficulty grasping the contents of some modules. None of the lecturers were aware of the entry requirements for the course as the university had never been open about how they selected students. The lecturers highlighted the need to adapt their teaching to students' academic level. There was no evidence of students getting career guidance on optometry.

\section{Teaching Context}

This theme was contextualized by the teaching practice of lecturers and student-faculty interactions.

\section{Teaching Practice of Lecturers}

This is composed of the lecturers' academic background and prior clinical and teaching experience. Their clinical experience varied from no experience to 12 years. Only one Colombian lecturer had any prior teaching experience. The lecturers used different methods and assigned different levels of importance to the various tests for refraction, with some being omitted completely. This created confusion among students. The general view was that the Colombian lecturers gave more importance to diagnosis of ocular disease and therapeutics and less importance to binocular balancing tests and dispensing. All the lecturers stated the need for a set protocol for tests in clinics that the lecturers have to follow.

\section{Student-Faculty Interactions}

The predominant view was that the lecturers provided support by coaching and guiding students.

\section{Clinic Conditions}

The factors identified included clinic supervision and feedback, assessment methods, and the lack of standardized patients.

\section{Clinic Supervision and Feedback}

The shortage of faculty and lack of time for supervision and feedback were deemed to have an influence on student performance.
There was insufficient time to address clinical errors so that students could learn from them.

\section{Assessment}

Every patient examination by each student was routinely graded as a 50-minute "mini-test" and the results were used for formative assessment. This made the students very nervous in following the protocol and caused many students to allocate time poorly, with exaggerated emphasis on history and symptoms and insufficient time for refraction and other tests, leading to a failure to address the patient's primary concerns. The lecturers mentioned that the theory examinations were set with appropriate levels of difficulty.

\section{Patients}

Other influences included lack of patients, especially in the first few months of clinical sessions (affecting cohort A primarily) and principally in the binocular vision clinic. Students had to bring their own patients either from their visits to the "communities" or their friends. The lack of standardization of patients especially during assessments affected performance.

\section{Existing Operating Health Care Context}

This was contextualized by the nature of optometry practice, the eye health conditions in Mozambique, and the patient role and experience of health care.

\section{Nature of Optometry Practice}

The optometry course needed to be adapted to better address the needs of the population, and this was observed to have affected student performance. It was suggested that students need to better understand barriers that exist to access of eye care (including cost, accessibility, awareness, and culture).

\section{Eye Health Conditions in Mozambique}

Three of the lecturers expressed doubts on whether the students were capable of treating the eye health conditions of patients they would see in an eye clinic.

\section{Patient Role and Experience of Health Care}

The predominant view was that there was a lack of public health awareness in eye care, and by the time the patients came to the clinic, their eye conditions were advanced to the point that little treatment could be offered.

\section{Student Evaluation Questionnaire}

Reliability analyses of the 30 variables of the pilot and 48 variables of the final questionnaire revealed a Cronbach $\alpha$ of 0.89 for the pilot and 0.86 for the final questionnaire, indicating good construct reliability. ${ }^{19}$ Table 3 summarizes the results with mea- T3 sures of mean and SD for the factors for cohort A and cohort B, Mann-Whitney test statistic, $z$, and the $\mathrm{p}$ value of statistical difference between the two cohorts. The results from the open-ended questions of the questionnaire are outlined in Table 4.

\section{DISCUSSION}

Overall, this study identified some significant factors affecting student performance in Mozambique. Three themes are discussed 
TABLE 2.

Lecturers' views on factors affecting student performance

Theme

1. Student learning context b. Lack of prior knowledge of the course and optometry practice c. Course workload and manageability

d. Student motivation
Qualitative statements

"More personnel available for support in clinic" (L1, L3, L4, L5, L6).

"More training, seminars and workshops for clinical practice for the lecturers and students" (L2, L8).

"More books" (L2, L5) and a "digital library" (L4, L8).

"The teaching has to be creative and resourceful. Translating English lecture notes in Portuguese and examining students in Portuguese was initially difficult" (L1).

"It is hard to read the assignments from the students. They all use the same one or two books; sometimes not even good books, just because they are in Portuguese" (L5).

"Their base in basic sciences and maths is quite low so it takes longer to explain things. I make more effort on topics they are going to deal with in everyday situation" (L3).

"They lack some basis of maths e $g$ without a calculator most of them don't do any kind of calculations, even the more basic ones. And even when they have a calculator some of them lack the basic principles to do the right arithmetic. Some more knowledge of Portuguese would be great. They misspell a lot, I cannot correct them all. If I did I would not do anything else" (L4).

"I had to slow down my speed of teaching and lower my expectation on how much they knew. They lack basic skills in core subjects. You have to be very patient and resourceful" (L5).

"The admission level is very low. For newer intakes the university has changed something and now we are receiving better prepared students" (L4, L6, L8, L9).

"Most of the first cohort did not apply for optometry but for medicine and nutrition but did not get through" (L1).

"Of course if they had a better basic education it would be easier to deal with the program even more if we think that they still don't know what is going to be their final work in the Mozambican society" (L3).

"The difficulty for the students when they were admitted is they lacked prior knowledge of the course" (L7).

"The course load is manageable" (L1-L9).

"The course load is intensive but necessary as some of the students had very low basic skills" (L3, L5).

"Most of the students have a lot of interest and motivation as they are helping their community" (L2, L3).

"In general students are motivated and engaged in the class. I think they value the fact that they can study for a qualified profession. Some also just want to have a good job" (L6).

"We need a protocol. In Colombia they do not carry out binocular tests regularly so the students get confused when we ask them to carry them out" (L4).

"All lecturers need to be at the same level clinically. We should all pass through an induction process where everyone has the same basic clinical level and knowledge of the protocol before starting to teach" (L1).

"We can cause confusion just from our different ways of doing things e g everyone has their own way of measuring pupillary distance. We have to give the students a clear protocol" (L3).

"A little bit of pedagogic experience would help. A lot of the differences are due to practical and professional experience of the lecturer. I attempt to clarify the contradictions with other lecturers and abide by the given protocol" (L6). 
TABLE 2.

(Continued)

Theme

Qualitative statements

ii. Student-faculty interactions

"Our time here is to support them. They come and find us in their free time. It's different from being at home where there were many more lecturers and many more students" (L2).

"The students and lecturers have very close relationships. The students call us on our mobiles if they have any doubts. We have to hold their hands" (L3).

\begin{tabular}{cc}
\hline 3. Clinic conditions and & i. Clinic supervision \\
assessment & and feedback
\end{tabular}

ii. Assessment

iii. Patients

4. Existing operating health care context i. Nature of optometry practice

ii. Eye health conditions in Mozambique

iii. Patient role and experience of health care
"Most of the clinics I had to supervise nine students on my own. I was exhausted. There was no time for feedback. I was called upon for other duties whilst I was supervising so sometimes the students would be left on their own" (L1).

"There is not enough time dedicated to student supervision. I am usually jumping around saying today I will evaluate this test for this student and next week I will grab this student. We need more lecturers involved in direct contact with the students in clinic" (L5).

"It's very difficult to evaluate the clinic. Most days there are 6 or more students to 1 lecturer. It's not enough. Most days I will evaluate one student, then I will get interrupted, something might not be working, and then there is never time for feedback for the other students. Sometimes the refraction or management of the patient is so bad you can't talk in front of the patient. I write it in their feedback sheet, but I don't know if they read them. I hope they do" (L6).

"They always make the same mistakes with cross-cylinder by not giving clear instructions and moving the axis of the cylinder until the patient says the vision is better" (L5).

"We are very strict. If a mediocre student passes, that's a bad 'product' of the university' (L1, L2, L3, L5).

"Every patient the students see is a test. They are always under a lot of pressure and more interested in finishing the protocol than in managing the patient. The tests should be less frequent with a lot more time for feedback" (L7, L9).

"Initially students brought friends and family members for eye exams. On some days there would be no patients at all" (L1).

"Students do not invite patients from the 'community' if they think they have a severe problem, as they are scared of getting a lower mark" (L2).

"We don't see many patients in the binocular vision clinic. Patients don't turn up after the initial consultation. The students need good exposure and experience with treating e $\mathrm{g}$ amblyopia but there are very few children in the clinics and the ones we see don't turn up for follow-up appointments" (L4).

"The course needs to be tailored to address the needs of the community and include aspects of local knowledge for students to communicate with the patients and give appropriate advice" (L9).

"They should attend an advanced refraction course concentrating on dispensing, binocular vision and low vision" (L1, L2).

"There is no supervision once the students graduate. The challenge for them once they graduate is how many patients they will be able to manage. Will they be able to provide spectacles, manage pathology?" (L3).

"We have to increase awareness of eye care within the population especially in the case of prevention" (L1, L2, L3, L5, L7, L9).

"We should be carrying out school screenings and having presentations in the communities about eye care" (L9). 
TABLE 3.

The mean, SD, and $p$ value of the student evaluation questionnaire

Agreement scale ( 1 = strongly disagree, 5 = strongly agree)

Cohort A, Cohort B,

Lecturers

The lecturers had sufficient knowledge of the content/area that they were teaching

The lecturers related to me in ways that promoted mutual respect

The lecturers stimulated my interest in the program

The lecturers were well prepared

The lecturers provided adequate opportunities for questions and class discussion

The lecturers were available to offer support outside of lecture times

The lecturers provided useful feedback on my progress of the courses throughout

the program

The lecturers showed genuine concern for the students and their learning

mean (SD)

mean (SD)

$z \quad \mathrm{p}^{*}$

Learning

The modules gave a detailed description of the theoretical aspect of the course

The workload was manageable

I had enough time for self-study during the program

The overall content of the program was appropriate to the practice of optometry

The content was at an appropriate level for an optometry degree

The basic science courses delivered in the first year were adequate background

to the professional and clinical course

There was a clear understandable link between the courses

The theoretical knowledge is adequately linked to the practice of optometry

The clinical work was well coordinated with the material covered in lectures and/or seminars

I was able to apply the theoretical concepts from lectures to the clinical situations

There was enough time allocated for the clinical aspect of this program

The level of clinical training is adequate

I feel confident about my clinical skills

$3.89(0.93)$

$4.22(0.67)$

3.67 (1.11)

$3.89(1.17)$

3.89 (1.36)

$4(0.71)$

3.22 (1.09)

$3.56(1.23)$

$4.12(0.41)$

4 (0.63)

$4(0.63)$

$4(0.63)$

4 (1.10)

$4.67(0.52)$

$3.83(0.75)$

$4(0.89)$

$-0.49$

0.67

0.62

$\begin{array}{ll}-0.45 & 0.65\end{array}$

$0.19 \quad 0.85$

0

$-1.81$

1

$-0.97$

0.07

0.33

$-0.51$

0.61

3 (1.12)

$2.33(1.22)$

1.89 (1.78)

$4.11(0.6)$

$4(0.71)$

$3(1.32)$

$3.11(1.17)$

$3.89(0.93)$

3.67 (1.12)

$3.83(0.98)$

$3.33(0.82)$

1.78 (1.89)

$4.33(0.52)$

$4.33(0.52)$

3.83 (0.98)

$-1.54$

$-1.59$

$-1.06$

0.12

0.11

$-0.71$

0.29

$-0.94$

0.48

(0.7)

$-1.26$

0.35

0.21

$4.17(0.75) \quad-1.80$

$4(0.63)$

$-0.07$

0.07

$3.83(0.98)$

$-0.26$

0.95

0.80

\author{
$4(0.71)$
}

$2.89(1.17)$

$3.67(0.87)$

$4.22(0.67)$

\title{
$4(0)$ \\ $4(0)$
}

$3.83(0.98)$

0

1

$4.33(0.52)$

$-2.17$

\section{Assessment}

There was a good link between what we learnt in class and what we were assessed on

The way my progress was assessed (assignments, examination, practical) gave a fair reflection on my knowledge and understanding

The in-class tests and assignments prepared me for the final examinations

I received constructive criticism on my performance in assessments

I received timely feedback on my performance in assessment

Equipment, resources, and infrastructure

There was adequate access to equipment needed to complete assignments

Equipment used was reliable and in working order

There was adequate opportunity to use the equipment within the specified clinic time

The lecture and tutorial rooms were adequate for the program

The laboratories were appropriate for the program

The library facilities/resources were adequate

The teaching resources (course manuals and PowerPoint) were adequate

Program in general

In general, this was an excellent program

Overall, the program exceeded my expectations

I would recommend this program to others

$3.67(1.12)$
$3(1.5)$

$4.17(0.41)$

$-0.53$

0.59

$-0.27$

0.79

$3.67(0.87)$

3.56 (1.24)

$4(0)$

$-0.80$

0.42

$4.33(0.52)$

$-1.27$

0.21

2.67 (1.41)

$4.5(0.55)$

$-1.61$

0.11

$4.5(0.55)$

$-1.82$

0.07

$4(0.63)$

$-1.84$

0.07

\begin{tabular}{lrrl}
$4.11(0.6)$ & $4(0.10)$ & -0.13 & 0.89 \\
$4.11(0.6)$ & $4.17(0.41)$ & \multicolumn{1}{r}{-0.15} & 0.88 \\
$4.33(0.5)$ & $4.33(0.52)$ & 0 & 1 \\
$3.89(0.33)$ & $4(0.63)$ & -0.42 & 0.67 \\
$4.56(0.53)$ & $4.17(0.75)$ & 1.05 & 0.29 \\
$2.78(1.30)$ & $3(1.26)$ & -0.38 & 0.71 \\
$3.22(0.97)$ & $4.17(0.41)$ & -2.05 & $0.04 *$ \\
\hline & & & \\
$3.67(0.5)$ & $4.17(0.41)$ & -1.83 & 0.07 \\
$3.67(1)$ & $3.83(0.75)$ & -0.31 & 0.75 \\
$3.89(1.27)$ & $3.83(0.75)$ & 0.57 & 0.57 \\
\hline
\end{tabular}

*Significant at $p<0.05$.

here: the student learning context (resources, student academic background, admission procedures, career guidance, and workload), teaching context, and clinic conditions.

Only four students passed the competency assessment. This was not a high-stakes examination but an external evaluation of the factors that affect student competence and performance. The quality of graduates in Mozambique has been recognized as being lower than regional and international parameters. ${ }^{21}$ Because of these evaluations, the final-year students attended a 1-week intensive course in retinoscopy, subjective testing, and binocular balancing before graduation.

It was originally anticipated that the optometry students would have sufficient English language skills for the program to be im plemented through English. The teaching resources originally available through the partners were in English. Although English is taught routinely in secondary school education in Mozambique, ${ }^{22}$ it was quickly noted that student language skills were insufficient and that the education program would need to be conducted in 


\section{TABLE 4.}

Open-ended responses to the student evaluation questionnaire

\begin{tabular}{|c|c|c|}
\hline Categories & Responses & Students $(\mathrm{N}=15), \mathrm{n}(\%)$ \\
\hline \multirow{3}{*}{$\begin{array}{l}\text { How would you rate the overall difficulty } \\
\text { or ease of this program? }\end{array}$} & Extremely difficult & $3(20)$ \\
\hline & Somewhat difficult & $11(73)$ \\
\hline & Neither easy nor difficult & $1(7)$ \\
\hline \multirow{3}{*}{$\begin{array}{l}\text { What prior preparation was necessary } \\
\text { to take this program? }\end{array}$} & English & $2(13)$ \\
\hline & Sciences and maths & $2(13)$ \\
\hline & Information about the course and its curriculum & $8(53)$ \\
\hline $\begin{array}{l}\text { Were the requirements for entering the program } \\
\text { made clear to you before starting the course? }\end{array}$ & No, the requirements of the course were not clear & $13(87)$ \\
\hline How can the lecturers improve on teaching? & $\begin{array}{l}\text { Provision of student support (including listening } \\
\text { to the students, helping weaker students, and } \\
\text { being patient and understanding with the students } \\
\text { when they have difficulties) }\end{array}$ & $12(80)$ \\
\hline \multirow[t]{4}{*}{ How can the learning process be improved? } & More time in clinics and tests & $3(20)$ \\
\hline & More lecturers & $3(20)$ \\
\hline & Connecting theoretical lectures to clinical practice & $2(13)$ \\
\hline & More relevant course notes & $2(13)$ \\
\hline \multirow{2}{*}{$\begin{array}{l}\text { How can the program assessment system } \\
\text { be improved? }\end{array}$} & Reducing the quantity of "mini-tests" & $6(40)$ \\
\hline & More time should be given to the students in clinic & $2(13)$ \\
\hline $\begin{array}{l}\text { How can equipment, resources, and infrastructure } \\
\text { be improved? }\end{array}$ & Better library resources & $1(7)$ \\
\hline \multirow{4}{*}{$\begin{array}{l}\text { What did you like most about the program } \\
\text { in general? }\end{array}$} & Clinical experience & $6(40)$ \\
\hline & Availability of clinical resources & $4(27)$ \\
\hline & Experience of working with an international faculty & $4(27)$ \\
\hline & Lecturer support & $1(7)$ \\
\hline
\end{tabular}

Portuguese or Spanish. English materials, therefore, were urgently translated into Portuguese and made available to faculty. Therefore, there is a statistically significant difference in the responses to the availability of teaching resources between the two cohorts. This issue was addressed after the piloting of the questionnaire for cohort A.

The inadequacy of the library facilities was established from both the interviews and questionnaires. There are limited optometryrelated textbooks available in Portuguese or Spanish and 55 computers at the optometry campus at UniLúrio for more than 700 students. Recurrent power outages, security issues, and restrictions in Internet connectivity, however, meant access to online journals, databases, textbooks, and other learning resources was limited, even when the computers were functioning. These deficiencies in libraries and information technology, common in other universities in sub-Saharan Africa, deny students the possibility of bypassing older learning methods to benefit from the rapidly advancing developments in Internet-based learning. ${ }^{23,24}$ The recommendation to UniLúrio is to invest in more computer facilities on campus, better Internet infrastructure, faster Internet connections, and the professional expertise to help students to access online resources. $^{24,25}$

In Mozambique, the education system is mainly characterized by weak performance as a whole, high grade repetition, high dropout rates, high pupil-teacher ratios, and a low percentage of qualified teachers. ${ }^{26}$ The variable and generally weak level of secondary education in Mozambique has necessitated the incorporation of a science-focused preparatory year at two medical schools in Mozambique, which affords students from poorer areas and weaker secondary schools the opportunity to study further education. ${ }^{4,23}$ This study has established that student preparation for the course, especially the low basic level of maths and sciences, was not ideal at the time of entry to the program. A preparatory year is therefore recommended to strengthen and homogenize student knowledge.

Admission and selection processes of students in health sciences have been identified as critical factors to address academic success and student retention rates. ${ }^{24,27}$ Selection of students is a challenge for health professions schools everywhere, particularly when criteria are shaped by social policy initiatives such as uneven distribution of health workers. ${ }^{24}$ To have graduates work throughout the country, there is a responsibility to recruit and select students from all the provinces. The pedagogical director in UniLúrio stated that students were selected on their geographical origin rather than a minimum mark. This has resulted in the new optometry graduates working in 7 of the 11 provinces in Mozambique at present, which is positive and indeed necessary given the paucity of resources in all provinces. To ensure that students with the necessary competencies are accepted in the program, it is recommended that the selection process is made more transparent and that more stringent admission criteria are applied compared with the present level.

Only one student had selected optometry as their first choice in response to a demographic questionnaire in 2010 administered 
to 27 students from the first two cohorts. ${ }^{28}$ The profession of optometry did not exist in Mozambique, and the course of optometry was only newly available to secondary school graduates for consideration. The lack of proper career guidance could result in poor academic performance. ${ }^{7}$ Appropriately planned career guidance, course outlines in a prospectus, and study guides for all the taught modules would also assist in generating increased secondary school interest in optometry and will assist students to make better informed decisions and choose degree programs suited to their ability and interests.

Heavy student workload was another factor to emerge from the questionnaire. Cohort $\mathrm{A}$ averaged $37 \mathrm{~h} / \mathrm{wk}$ of contact time AQ3 (minimum, 30; maximum, 44), whereas cohort B had 32 hours (minimum, 24; maximum, 42). About $55 \%$ of the course was theoretical, and $45 \%$ was practical. In courses allied to medicine in the United Kingdom, the average number of contact hours is $23 .{ }^{29} \mathrm{~A}$ curriculum review in 2013 has reduced the contact hours to 29 (minimum, 24; maximum, 32) with $49 \%$ theoretical and $51 \%$ practical. Some of the factors involved in the greater number of hours in the curriculum included poor secondary school education, inadequate entry level, and the inclusion of courses in Portuguese, English, and basic sciences in the first two semesters to account for the dropped preparatory year for cohort B. Increasing the average university entrance scores would ensure that the enrolled students have better ability to cope with the workload..$^{30} \mathrm{~A}$ reduction in the number of contact hours, however, would seem a prudent recommendation to the university based on international trends and norms for allied health care education programs. ${ }^{29}$

Optometry is still a developing profession in most Spanish- and Portuguese-speaking countries, with varying scope of practice challenges. Lecturers from these countries had different training and different perspectives as to training priorities. ${ }^{31-33}$ Because of the lack of faculty training or pedagogic skills assessment before recruitment, the staff did not have equivalent clinical competencies. In Colombia, the scope of practice for optometrists includes the evaluation, diagnosis, prognosis, pharmaceutical treatment, and rehabilitation of vision problems. ${ }^{31}$ Spain and Portugal do not allow the use of pharmacological agents. The focus of their courses is refraction and optics. ${ }^{32,33}$

Cohort A had most of their clinics with Colombian lecturers and hence have benefited from good diagnostic and therapeutic knowledge at the expense of binocular balancing tests for refraction. This has been demonstrated in the statistically significant difference in binocular balance between the two cohorts in Table 1. Although efforts were made to provide continuous clinical education to faculty, this study highlights the need to more comprehensively address this salient issue. Competent staff enhance student learning; hence, faculty should be encouraged to seek opportunities for continuing professional development as well as in the area of teaching and learning. ${ }^{34}$ Increasing the ratio of supervisors to students and allocating feedback time after every patient seen by the student would ensure that flawed or missed techniques can be observed and corrected.

The clinical experience of the first intake of students was compromised relative to subsequent intakes in terms of the quality and level of exposure to patients in clinic. This was an inevitable problem given the lack of awareness of optometry in the country and within the community the student clinic serves. Increasing the awareness of the existence of the optometry clinic resolved these issues for cohort $\mathrm{B}$, as is evidenced in the statistically significant difference in reported satisfaction with the clinical aspects of the program between the two cohorts. It is realistic to expect that this pattern will continue to improve over time as the clinic builds a database of patients available for student examination and assessments.

A valid, reliable student assessment system is another critical challenge facing African schools. ${ }^{24}$ There is no literature on the frequency of clinical assessment in optometry clinics in developing countries. In this context, the university set the criterion that every patient had to be assessed as is the case in medical courses in Mozambique. ${ }^{35}$ This had an indirect effect of students selecting patients with low/no refractive error, as they knew they were getting assessed. For some patients in the eye clinic at UniLúrio, this was their first eye test. Their interpretation of the practitioner's questions, their lack of past experience, and their inability to discriminate small differences can all lead to inappropriate feedback. ${ }^{36}$ Other patients had severe, untreated pathology or complex refractive errors. When the students examined these patients, it resulted in poor performance as they were difficult patients to manage.

The lack of standardized patients and the lack of practice on patients with moderate/high refractive error have posed challenges in student competency development. ${ }^{37}$ As the clinic database has developed, the practice of students self-selecting their patients has now ceased. Because of the resource constraint of a lack of supervision and the range of patients seen, it is recommended that, in the first semester of clinical practice, the students concentrate on a problem-focused eye examination, addressing the patients' concern. Broader domains of competence (e.g., history, communication, and patient advice) could then be assessed to develop the students' professional practice. The training has to be contextually relevant to the type of conditions and patients they encounter (e.g., low vision, high refractive errors, and binocular vision).

However, despite the apparent challenges, the lecturers stated that student motivation was high, and they operated an "opendoor" approach for student support with the students calling on them in their free time and even during weekends. There is agreement in the literature that supporting students is an important function of the lecturer. ${ }^{38}$ Adapting the support system to be based on individual students' learning needs by having tutorials and regular feedback sessions would address the students' expectations of lecturer support. ${ }^{38}$

These evaluations have allowed us to explore and better understand the complex nature of the factors that have affected optometry students' academic performance in the only optometry training program in Mozambique. More research needs to be conducted to see if these factors are representative of the optometry students from the new optometry departments in developing countries with similar health care context and uncertain scope of practice.

There are some limitations to this study. The data related to the performance of only 15 students and responses from those students and nine lecturers from one university. They, however, represent $100 \%$ of the final-year students across two successive cohorts and the entire faculty when the evaluations took place. 
Moreover, the study has concentrated on factors affecting the teaching, learning, and existing health care context and did not take other demographic factors into account.

Received October 19, 2014; accepted March 25, 2015.

\section{REFERENCES}

1. Penisten DK. Optometric education and optometry in Africa. J Am Optom Assoc 1993;64:726-9.

2. Oduntan OA, Mashige KP, Kio FE, Boadi-Kusi SB. Optometric education in Africa: historical perspectives and challenges. Optom Vis Sci 2014;91:359-65.

3. A Global Competency-Based Model of Scope of Practice in Optometry. World Council of Optometry, 2005. Available at: http://www.world optometry.org/filemanager/root/site_assets/governance_documents/ global_competencies_model.pdf. Accessed March 21, 2015.

4. The Sub-Saharan African Medical Schools Study (SAMSS). Faculty of Medicine Catholic University of Mozambique SAMSS Site Visit Report; 2009. Available at: www.samss.org. Accessed February 7, 2014.

5. Human Resources for Health Situation in Mozambique, Ferrinho P, Omar C. The World Bank: Africa Region Human Development Working Paper Series No. 91, 2006. Available at: http:// www.hrhresourcecenter.org/node/1710. Accessed June 4, 2012.

6. Sousa FJr., Schwalbach J, Adam Y, Gonçalves L, Ferrinho P. The training and expectations of medical students in Mozambique. Hum Resour Health 2007;5:11.

7. Maphosa C, Sikhwari TD, Ndebele C, Masehela M. Interrogating factors affecting students' epistemological access in a South African university. Anthropologist 2014;17:409-20.

8. Ofori R, Charlton JP. A path model of factors influencing the academic performance of nursing students. J Adv Nurs 2002;38:507-15.

9. Prajapati B, Dunne M, Bartlett $H$, Cubbidge R. The influence of learning styles, enrolment status and gender on academic performance of optometry undergraduates. Ophthalmic Physiol Opt 2011;31:69-78.

10. Biggs JB. From theory to practice: a cognitive systems approach. High Educ Res Dev 1993;12:73-85.

11. Pascarella ET, Terenzini PT. Predicting voluntary freshman year persistence/withdrawal behavior in a residential university: a path analytic validation of Tinto's model. J Educ Psychol 1983;75:215-26.

12. Biggs JB. Approaches to the enhancement of tertiary teaching. High Educ Res Dev 1989;8:7-25.

13. Ramsden P, Moses I. Associations between research and teaching in Australian higher education. High Educ 1992;23:273-95.

14. Trigwell K, Prosser M. Towards an understanding of individual acts of teaching and learning. High Educ Res Dev 1997;16:241-52.

15. Ramsden P. A performance indicator of teaching quality in higher education: the Course Experience Questionnaire. Stud High Educ 1991;16:129-50.

16. World Health Organisation. World Medical Association Declaration of Helsinki. Ethical principles for medical research involving human subjects. Bull World Health Organ 2001;79:373-4.

17. Pass/Fail Standards. National Board of Examiners in Optometry (NBEO), 2011. Available at: https://www.optometry.org/passfail.cfm. Accessed February 6, 2014.
18. Leinonen J, Laakkonen E, Laatikainen L. Repeatability (test-retest variability) of refractive error measurement in clinical settings. Acta Ophthalmol Scand 2006;84:532-6.

19. Hair J, Black W, Babin B, Anderson R, Tatham R. Multivariate Data Analysis, 6th ed. Upper Saddle River, NJ: Pearson Education Inc; 2006.

20. Creswell JW, Miller DL. Determining validity in qualitative inquiry. Theory Pract 2000;39:124-30.

21. Education Strategic Plan 2012-2016. Republic of Mozambique Ministry of Education, 2012. Available at: http://planipolis.iiep.unesco.org/ upload/Mozambique/Mozambique_Education_Sector_Plan_2012-2016.pdf. Accessed March 21, 2015.

22. The EFA 2000 Assessment: Country Reports: Mozambique. Part 1: Descriptive Section. UNESCO, 2000. Available at: http://www.unesco. org/education/wef/countryreports/mozambique/rapport_1.html. Accessed February 7, 2014.

23. Mullan F, Frehywot S, Omaswa F, Buch E, Chen C, Greysen SR, Wassermann T, Abubakr DE, Awases M, Boelen C, Diomande MJ, Dovlo D, Ferro J, Haileamlak A, Iputo J, Jacobs M, Koumare AK, Mipando M, Monekosso GL, Olapade-Olaopa EO, Rugarabamu P, Sewankambo NK, Ross H, Ayas H, Chale SB, Cyprien S, Cohen J, Haile-Mariam T, Hamburger E, Jolley L, Kolars JC, Kombe G, Neusy AJ. Medical schools in sub-Saharan Africa. Lancet 2011;377: 1113-21.

24. Burdick W. Challenges and issues in health professions education in Africa. Med Teach 2007;29:882-6.

25. Isaacs S, Hollow D, eds. The eLearning Africa 2012 Report. Germany: ICWE; 2012. Available at: http://www.elearning-africa.com/pdf/ report/ela_report_2012.pdf. Accessed October 3, 2014.

26. SACMEQ Reports. Available at: http://www.sacmeq.org/sacmeqmembers/mozambique/sacmeq-reports. Accessed March 6, 2014.

27. Institute of Medicine (US) Committee to Increase Minority Participation in the Health Professions; Ein Lewin M, Rice B, eds. Balancing the Scales of Opportunity: Ensuring Racial and Ethnic Diversity in the Health Professions. Washington, DC: National Academies Press; 1994.

28. Chan VF, Loughman J, Moodley VR, Bilotto L, Naidoo K. Student educational background, perceptions and expectations towards optometry: an emerging eye health profession in Mozambique. Optometric Educ 2015;40:104-9.

29. Soilemetzidis I, Bennett P, Buckley A, Hillman N, Stoakes G. The HEPI-HEA Student Academic Experience Survey 2014. Heslington, York, UK: Higher Education Policy Institute, Higher Education Academy; 2014. Available at: http://www.hepi.ac.uk/2014/05/21/hepihea-2014-student-academic-experience-survey/. Accessed September 12, 2014.

30. Bowyer K. A model of student workload. J High Educ Policy Manag 2012;34:239-58.

31. Leasher J, Pike S. Optometry in the Americas. In: Hatch S, Whitener J, McAlister WH, Block S, eds. Optometric Care within the Public Health Community. Cadyville, NY: Old Post Publishing; 2009. Available at: http://webpages.charter.net/oldpostpublishing/oldpostpublishing/ Sect $\% 205, \% 20$ Optometry\%20in $\% 20$ the $\% 20$ Americas $\% 20$ by $\%$ 20Leasher\%20and\%20Pike.pdf. Accessed March 21, 2015.

32. Associação de Profissionais Licenciados de Optometria (APLO). Que faz um Optometrista? [Portugese] Available at: http://www.aplo.pt/Sobrea Optometria/QuefazumOptometrista.aspx. Accessed March 7, 2014.

33. Consejo General de Colegios de Ópticos Optometristas (CGCOO). Available at: http://www.cgcoo.es/. Accessed March 7, 2014. 
34. Bland CJ, Seaquist E, Pacala JT, Center B, Finstad D. One school's strategy to assess and improve the vitality of its faculty. Acad Med 2002; 77:368-76.

35. Ayas H. Faculty of Medicine Catholic University of Mozambique: 2009. Available at: http://www.samss.org/samss.upload/wysiwyg/Full\% 20Site\%20Visit\%20Reports/Catholic\%20-\%20Mozambique.pdf. Accessed February 6, 2014.

36. Harris WF. Subjective refraction: the mechanism underlying the routine. Ophthalmic Physiol Optics 2007;27:594-602.

37. Wass V, Van der Vleuten C, Shatzer J, Jones R. Assessment of clinical competence. Lancet 2001;357:945-9.
38. Gidman J. The role of the personal tutor: a literature review. Nurse Educ Today 2001;21:359-65.

Kajal Shah

Optometry Department Dublin Institute of Technology

19A Kevin Street

Dublin 8

Republic of Ireland

e-mail: kajshab@aol.com 


\section{AUTHOR QUERIES}

\section{AUTHOR PLEASE ANSWER ALL QUERIES}

$\mathrm{AQ1}=$ Please expand VA here if it is indeed an acronym.

AQ2 = Shouldn't the number of questions for the five categories total 48 (based on "...final questionnaire having 48 items broken down into evaluation of five key categories")? They only add up to $40(9+14+6+8+3)$. Please confirm.

AQ3 = Shouldn't "had 32 hours" be changed to "averaged $32 \mathrm{~h} / \mathrm{wk}$ "?

\section{END OF AUTHOR QUERIES}

